\title{
THEATER AND HEALTH EDUCATION: REPRESENTATION IN SELECT PLAYS OF MAHESH DATTANI
}

\author{
Asoke Howlader \\ Department of Humanities and Social Sciences, National Institute of Technology Durgapur, West Bengal \\ Arindam Modak \\ Department of Humanities and Social Sciences, National Institute of Technology Durgapur, West Bengal \\ Subrata Saha \\ Department of Economics, Raiganj University, West Bengal
}

\begin{abstract}
Theater plays a crucial role to represent the life and manners of a particular society. It acts as an informal tool for developing consciousness and promoting empowerment through education. Contemporary theater in India is no exception to this. It has the efficacy to build critical awareness among common people in general and women in particular. It critiques the social inequality and opens up the scope for bringing consciousness about gendered violence prevalent in contemporary Indian society. From 1970s onwards, the emergence of urbanization and industrialization had offered various opportunities for people irrespective of gender differences. Yet, it could not suppress the 'other side' of violence in Indian society. Mahesh Dattani, a pioneer in the world of modern Indian English Theater, is highly regarded as a social critic of contemporary urban life and manners. He sincerely presents dysfunctional families, individual dilemmas and societal problems, and gender issues including forbidden issues in his plays. As a conscious dramatist, Dattani reveals childhood maltreatment in his plays which focus on physical and mental illnesses among victims. He tries to sensitize the common people by representing the impact of discrimination on health as it is seen to be fatal in women. The present paper intends to analyze the impact of gender bias on women's health as represented by Mahesh Dattani in his plays - "Tara" and "Thirty days in September." In doing so, it embraces the educational implication of dramas through theater.
\end{abstract}

Keywords: Theater, gender bias, childhood maltreatment, trauma, and health education.

Article Received: 10 August 2020, Revised: 25 October 2020, Accepted: 18 November 2020

\section{INTRODUCTION}

Education is one of the crucial factors of women empowerment because it motivates them to react to the challenges, to reorganize their stereotypical role and modify their life. Long after the Vedic period the interest in women's education in India was revived during the British period. Famous persons like Raja Ram Mohan Roy, Iswar Chandra Vidyasagar, Jyotiba Phule, and Baba Saheb Ambedkar emphasized on formal education as the necessary tool for women's education in India. However women's education got a momentum after the post- independence era by the implementation of various government initiatives. To offer education to everyone, EFA (Education for All) programme was launched in 2002 by the Government of India after the 86th Constitutional Amendment. It proposed for free and compulsory education from age 6-14 as the fundamental right of every Indian child. But the condition of female education has not improved according to desired level for women.

In this age of globalization formal mode is not the only way to offer education. Recent opinions show that education must not be restricted 
within classroom, and given without proper social setting. Mass media are such powerful domains which contribute to the social background of education. In recent times, mass media prove that education is not limited to four walls of the classroom. In fact, mass media are the educational device for the common people. Irrespective of caste, creed, gender, and spatialtemporal difference mass media prove as a significant means for the education to mass. Common public collects huge information from the wide-ranging mass media and utilizes them for educational purposes. It is noteworthy to tell that mass media may replace the actual classroom teaching in near future. Theater is one such mass media which guides common people in social environment. In contemporary India too, dissemination of education is not limited to formal mode. Different tools related to the informal mode of education have facilitated conscientization and empowerment of the general public. Theater is an outstanding example of mass media although it has been given less importance so far. Socially committed and gender conscious dramatists can represent women's issues by the fruitful use of theater and can stimulate awareness among masses for social change encouraging empowerment of women. Contemporary theater in India has developed from the contact between new theater movement of the 1960's and the modernist movement of that time. It revises not only male dominated view of life but also male oriented discourse. Social Realist Theater is the practice of everyday awareness and advancement. It also communicates the means of performances, modes of expression, and touching narratives of women.

\section{LITERATURE REVIEW}

Existing literature on contemporary theater of India mainly deals with the changing pattern of people's predicament in society and articulates their sufferings to mete out social justice and equality for them. Particularly, the traditional social structure treats women differently; whereas men enjoy all rights but they have refused them to women. Culture has also assisted to deny social equality to women. They have also been vulnerable to gendered deprivations. They have been subject to aggression and mistreatment such as harassment, sexual abuses, rape, dowry deaths, sati, mental and corporeal suffering. In India, women are tortured, forcibly married, exploited, and humiliated. These issues are openly sketched in socially conscious dramas. But the role of theater as an informal means of developing consciousness among women is not touched so far in detail. Different studies show social realist theater as a mode of representation of women's subjugation in contemporary Indian sociocultural construct.

Agnihotri (1990) asserts that drama has the unique power to communicate the audience and motivate them for raising protest against social injustice.

J. Campbell (1995) proposes that educationist John Dewey emphasized on the fact that education must not be restricted within teacher, and offered without social setting.

Tuntun Mukherjee (2005) suggests that women are attracted to theater due to their lack of education and male exclusivity in every field of society.

Basu Thakur (2013) sees theater as an effective tool to promote social development. The superiority of theater lies in its immediate response from masses. Thus it is essential to empower the marginalized people of India.

The thought-provoking gap in the current studies is that theater can be effectively used to promote education by stimulating awareness among women for their rights. The present paper intends to point out the overlooked aspect of theater which has the ability to promote women empowerment through education. This new scope can be traced in the chosen plays of Mahesh Dattani. The dramatic texts taken here for analysis are "Tara" and "Thirty days in September".

Mahesh Dattani seriously dramatizes the tragic and sorrowful condition of women through the poignant narrative of oppression and discrimination prevalent in society. This touching performance by the actors moves the hearts of the viewers through the humanistic appeal for social justice and equity. This claim for basic human rights - self-dignity, freedom of 
expression and equal position - raises awareness among all. It shows that theater has an educative value to bring consciousness for positive response.

\section{Women's Health Education through Conscientization}

Social Realist Theater intends to raise awareness to develop the social condition of women. It questions the established social realities and norms which are generally practiced against women. It aims at revolutionary changes in women's lives by educating them through dramatic representation. Mahesh Dattani improvises realistic mode to face traditional challenges, and draw support for the education of women through social consciousness. He has represented the participation of women in cultural performances. He articulates the sufferings of women, and addresses the social issues from gender perspective to draw attention of the local, national, and global communities. $\mathrm{He}$ highlights Indian family losing ground its values and the emptiness of Indian society. Gender demarcation and sexual abuse of children and even adolescents are acts that leave a person blemished for life when s/he begins to realize what had happened to him/her quite early in life. The present paper focuses on the role of theater to promote health education for women by critically studying the impact of gender difference on health in two select plays of Mahesh Dattani - "Tara" and "Thirty days in September".

\section{Tara: Physical Disability and Trauma}

Dattani has dramatized a near perfect patriarchal setting where all the key decisions are taken by chief of the family in "Tara". Mr. Patel entails his patriarchal influence on his children and wife though he himself became its prey. Bharti's father wanted male hirer to his assets and he discovered it in his grandson. He had used his power and forced doctor to give leg of girl to the boy. He had done partiality to Tara by giving all his possessions to the boy and excluded the girl from it. Thus, father of Bharti was more accountable for making Tara cripple, which leads to the tragedy of her life. Mr. Patel makes arrangement only for Chandan and not for Tara, because he makes out that man can carry on in the world on his own capacity. So, he tries to make him self-sufficient to stand in his life as a flourishing person. Mr. Patel wants his son to earn sufficient money to perform his manly role. The position of woman in our society is restricted inside the household to watch over their house. But the success of man is judged by society and it is a test to father make him a worthy man. The father like Patel could not think it as also necessary to make women booming in the outer world because it is a field limited for man only. Tara never likes this partiality of her father. So when Roopa comes she tells her that the men of her family still prefer old traditions to keep women at home. She says, "The men in the house were deciding on whether they were going to go hunting while the women looked after the cave." (CP 328)

Dattani has represented that mother herself is biased to her children on the basis of their gender. Bharati opines to give the leg of her daughter to her son. The difference in the boy and the girl is not made by society only but mother also makes such a differentiation in her children. Here, mother makes her daughter physically weak only because she loves more to her son. The surgery was dealt with the hidden purpose of Bharati's interest for the survival of the male child. The play is about the division between the inequality of the gender based classes of men and women. Tara is overlooked by Bharati, her mother. Bharati even takes risks which involve Tara's possible death. The gender prejudices of the society control her. The inhuman act of female infanticide in accordance with social rules is emphasized through social system and principles of conduct. Mr. Patel insists on distinguishing the gender roles in his family between both the Children Tara and Chandan.

The play "Tara", Dattani comments in an outspoken manner upon gender discrimination. There is gender prejudice due to the patriarchal dictatorial hegemony which is still dominant in the contemporary setup of the present times. The play is a appalling tale of the social injustice. The patriarchal society is always belligerent in doing wrong towards the members of the female gender. This is the root cause of inequity and it has remained same in spite of the development of human civilization from the times of the 
Stone Age to the present day of IT, nanotechnology and the time of globalization and privatization. The family bonds are broken by such an malevolence practice of gender discrimination. The socio-cultural customs have distorted and spoiled the ties of human relationships. Bharati's maternal love is sacrificed under the pressure of social conventions and discrimination. The idea of motherhood is also under the male control and the physical necessity of becoming a mother is monitored by the male patriarch. The play "Tara" presents the tension between the male self and the female self. In one of his interviews to Lashmi Subramanyam, published in "Muffled Voices: Women in Moden Indian Theatre" (2002) Dattani provides his own explanation beautifully:

"I see Tara as a play about the male self and the female self. The male self being preferred... in all cultures. The play is about the separation of self and the resultant angst." (pp. 88)

Gender demarcation due to physical difference between Chandan and Tara leaves mental scars in major characters of the play "Tara". Chandan's emotional crisis is presented in the play "Tara" quite graphically. The emotional tension of each of the four major characters is shown in the dramatic action of the play "Tara". All the three - Bharati, Mr. Patel and Chandan have suffered immeasurable sense of guilt. Each of these three characters seeks an outlet for thier guilt and of course, Tara's sufferings lead them to this stage. In "Tara", physical deficiency has been given too much weight. Tara has been shown helpless because she has a disability and is consequently denied the benefits of life. But Tara could have made her weakness, her strength and fight the society to secure a place of her own. She was a cheerful and active girl who had all the qualities as a common girl. If she had been given moral back up by her parents, especially her father, she might have shown like a star. Her father's keen interest for her brother's future and total ignorance towards her led her to think that she was inept for any productive work. In short, she tried to believe that her life was a trouble on this earth. This made her lose attraction in life altogether. Further she refuses to go to physiotherapy or fill forms for college.
Thus, physical disability due to gender difference leads to physic failure for Tara.

\section{Thirty days in September: Mental Health and Trauma}

Dattani's next play chosen here for discussion is "Thirty Days in September" which focuses on mental health through its touching delineation of child sex abuse in a family. It is influential and moving in its depiction of agony, distorted self and sexual trauma of the protagonist Mala. Mala experienced repeated molestation by her own maternal uncle, Vinay whenever he visited them or they visited him during her summer vacation. Mala is distressed when she finds her mother not paying attention to her ordeal, despite her constant attempts. Her mother's deaf ear, blind eye, silent heart and numb mind appear to be unnatural to Mala and as well to the audience. This emotional alienation worries Mala more than the trauma of the sexual abuse of her uncle. The mother only prays to Lord Krishna and Mala in her rage picks up the glass framed portrait of Lord Krishna and breaks into pieces. Her hatred towards her mother keeps mounting and hence she blames her for failing to defend her, for failing to offer maternal love and fulfilling her sense of duty.

Child sex abuse is an appealing, harmful and degrading assault on a child's body and mind, and thus results ultimately in betrayal. Mala charges her mother for not caring her and questioning her. She has lost all her poise in her mother. The victims of child sex abuse may lead to compelling immoral desires. Mala's disappointment transforms her into a negative personality and her sexual distortion is a result of repeated abuse faced by her. She changes men once in thirty days and before they discard her, she rejects them. In this way she tries to take revenge on the men folk. She finds her own way of living life as no one comes to her rescue. Mother could understand the feelings of the children before they articulate. Here, Mala finds her mother intentionally avoiding, listening to her. Mala does not find a shoulder to cry, a rescuer to rely on, not a person to share her emotional pain. Mala's mother Shanta admits her severe fault and tries to defend her silence, "how could I save her when I could not save myself" (3.55). Mala feels so worthless that she 
neither loves anyone nor is ready to receive love from anyone. The therapist suggests Deepak, "All she needs is some love and attention and she will be fine" (2.49). The psychologically disturbed Mala says to Deepak, that she sees her molester everywhere. For Mala, it is very difficult to be free of depression because she was repeatedly abused for a long time. So it took long time for Mala to get rid of her traumatic memories and tormenting emotions. Shanta and Mala consider themselves as impassive and lifeless vegetables and are unaffected by all feelings. Sexually abused victims undergo an array of symptoms: depression, guilt, rage, emotional breakdown, lack of self-respect and hopelessness. Mala develops herself into a sexual addict and wants to take revenge on the male and not mature enough to realize that she causes her own damage. Thus the play captures the condition of victims having difficulty in maintaining fruitful relationships. Some may not contact to men, some may destroy friendships and marriages and some may shun close relationships. When Deepak comes to safeguard Mala, she is unwilling to allow the true love of Deepak initially.

It is very alarming to experience that Mahesh Dattani's play seems to represent the protagonist Mala to expose how young girls transform themselves into sex workers. The play begins with Mala, interacting to her counselor, and the meeting between them offers a sketch of her as a very baffled person. Adolescence is always too complicated for a person to handle it properly. As it marks a shift from childhood to adulthood, it is a state of great mental uncertainty in a person because $\mathrm{s} / \mathrm{he}$ understands that $\mathrm{s} / \mathrm{he}$ is no more a child but at the same time not fully an adult, and that is why s/he does not make out what s/he should choose to do, and what outcomes it will have on the family, his/her siblings, age group or society. Mala frequently thought about her bitter incident of molestation by the hands of her uncle before her maturity. She is unable to liberate herself from the trauma of past experience and develops a deep guilt of victimhood. Mala tries to draw attention to him/her through exaggerated or unhealthy behavior. This attitude develops in her just due to her sense of loneliness. At the end of the play,
Deepak wants to assist her and invites her home so that she would be more relaxed and free. Mala turns down his request on the ground that she would not be able to free herself from the haunting memories of her uncle's act. It is clear from the interaction between Mala and Dipak that the former has developed a mania and negative outlook to her uncle's terrible act of abuse and is out to retaliate it by indicating other men.

Dattani dramatizes the condition of the victims' sexual abuse as dumb without the power, courage and conviction to fight against the abusers. Shanta's suffering is portrayed in subtle way and it is more hostile, dismal and long lasting than Mala's misery. She suffers abuse in the hands of her brother for ten years. Then the trauma of incest turns her lifeless object to make her husband leave her for another woman. For her survival, she has to ask for help only from her brother who has ruined her life. Her disgrace and agony holds her back from saving her daughter and that adds load as guilt on her. She suppresses all her pain with herself and bears Mala's words tolerantly and tries to escape from the pangs of incest by giving in to Sri Krishna. With Deepak's entry into Mala's life, Shanta discovers light at the end of the tunnel. So she attempts to arrange the marriage between Deepak and Mala. The trauma and guilt of exploitation deprives them of the essential qualities needed to live life in normal way. They become disappointed and depressed after realizing that there is no fault of their own.

The need of cooperation extended from outside is inevitable to help them out of the negative mental trap. They seek a caring hand and loving heart that pay heed to their feelings and problems. With regard to Shanta, She is alienated with her problems from her childhood. She cannot seek support from anyone sharing her suffering and even her husband is not trying to solve her problem rather he finds mistake with her for being sexually inactive and enjoys extra-marital relationship with another woman. With no backing, she has to live as a mute spectator to the exploitation of her daughter with tormented soul. Like a psychologist, Dattani reflects on the disintegrated self and its strange responses in this play. Every child needs to be 
nourished with kindness and love as well as attention and warmth. The lack of the care facilitates abnormal attitude to the surrounding and ultimately leads towards mental disorder. The child placed in inappropriate social and familial environment in terms of life and affection turns out to be hostile to the world showing hatred for positive cultural values and social conventions. The play is considered as a sensitive play, and it unveils the pain, hidden behind the silence of the protagonist(s). Mala feels that her mother is guilty for the pain from which she suffers. Shanta observes everything silently and she doesn't say a single word against her brother due to her compulsion.

Thus, the critical analysis of the chosen plays clearly proves that theater is one of the most powerful and informal mode of depiction of human life. It has the capacity to stimulate the conscience of the viewers. The viewers participate in the dramatic performances actively when the moving tale of suffering touches their hearts. The drama, being lively medium, represents the course of human experiences and relates us with character's hidden and complex pattern of human perception. The thirst to articulate human predicament and constant process of degradation forces the dramatists to change the usual course and reform the established norms and ideas of theater. The activist dramatist has the power of constructing spaces for recording dissent against the humiliation of humanity as a whole. Although theater has its limitations, it has undeniably raised the awareness about the woman's position in the society. The image of women characters by a Mahesh Dattani is always true to life and as such genuine. His plays are influential in their undertaking of more intricate issues and portraying topics concerning their daily life in greater intensity. Women education in India is a challenging issue as one must accept the fact of gender difference and inequity against women as social evil for long time. It aims to encourage women with the power to rethink conventional patterns and societal or religious beliefs that have generated oppression and marginalization. Theater can create an awakening environment to attain their power and dignity as prominent devices of change in society. Theater helps to identify the function of mass communication as any formal mode of communication and education denies acknowledging communication through performances as the goal for the advantage of the common public and their survival.

\section{CONCLUSION}

The present study particularly highlights the positive role of modern Indian theater as an informal tool to express the voice of the exploited and isolated women of contemporary India. It focuses on theater's efficacy of rising consciousness among women for promoting empowerment through education. Theater is a means of emancipation; it facilitates victims to break their silence. It is the meeting point of art, activism and social application and considers theater as a mechanism of women empowerment. Dattani's plays expose women's distinctive expression, their situation, and their ways of self-realization through communication. So education is also one of the basic needs of women for social development. Theater as the informal tool of education can be helpful to highlight problems of women and direct them for their fundamental human rights. Social Realist Theater proposes to consider women's issues from humanistic perspective.

\section{REFERENCES}

- Abraham, Taisha. (Ed.). (1998). Feminist Theory and Modern Drama. New Delhi: Pencraft International.

- Agnihotri, A. N. (1990). Protest as art: Contemporary Hindi drama. In S. Pandey \& F.

- Taraporewala (Eds.), Contemporary Indian drama (pp. 26-31). New Delhi: Indian Society for Commonwealth Studies, Prestige Books.

- Aston, Elaine. (1995). An Introduction to Feminism and Theater. London and New York: Routledge.

- $\quad$ Basu Thakur, Priyam. (2013, December). Theater for Development in Indian Context: An Introspection. Global Media Journal, 4 (2). 
- Beauvoir, Simon de. (1961). The Second Sex. London: Four Square Books.

- Campbell, J. (1995). Understanding John Dewey. Chicago: Open Court Publishing Company.

- Clark, R. E. (1992). Media use in education. In M.C. Alkin (Ed.), Encyclopedia of Educational Research (pp.805-814). New York: Macmillan.

- Dattani, Mahesh. (2000). Collected Plays. New Delhi: Penguin Books.

- Desai, N., \& Thakkar, U. (2004). Women in Indian Society. Delhi: National Book Trust.

- Gargi, Balawant. (1962). Theater in India. New York: Theater Art Books.

- Gupta, N.L. (2003). Women's Education Through Ages. New Delhi: Concept Publications Co.

- $\quad$ Keyssar, Helena. (1996). Feminist Theater and Theory. UK: Palgrave-Macmillan.

- Kulshreshtha, Indira. (1992). Indian Women: Images and Reflections. New Delhi: Blaze.
- Kumar, Nita. (Ed.). (1994). Women as Subjects: South Asian Histories. Charlottesville: University Press of Virginia.

- Pande, Mrinal. (1991). "Women in Indian Theater." The Subject is Woman. New Delhi: Sanchar.

- Rao, R.K. (2001). Women and Education. Delhi: Kalpaz Publications.

- Singh, A. (2013). Gender, Space and Resistance: Women and Theater in India. (T. T. Anita Singh, Ed.) New Delhi: D.K.Agencies.

- Subramanyam, L. (Ed.). (2002). Muffled Voices: Women in Modern Indian Theater. New Delhi: Har-Anand Publicatons Pvt Ltd.

- Upadhyaya, R. K. (Ed.). (1996). Women in 21st Century: Problems and Challenges. New Delhi: Harnam Publications.

- Walby, Sylvia. (1997). Theorizing Patriarchy. Cambridge: Polity Press. 